\title{
CLASSIFICAÇÃO E DESCRIÇÃO TÉCNICA DAS EMBARCAÇÕES PESQUEIRAS ATUANTES EM SANTARÉM, ESTADO DO PARÁ
}

\section{CLASSIFICATION AND TECHNICAL DESCRIPTION OF FISHING BOATS IN SANTARÉM, PARÁ STATE}

\author{
Diego Maia Zacardi ${ }^{1 *}$, Yohanna Gabriely Sousa Rabelo ${ }^{2} \&$ Luan Campos Imbiriba $^{3}$ \\ Laboratório de Ecologia do Ictioplâncton e Pesca em Águas Interiores, Universidade Federal do Oeste do Pará - Ufopa \\ *e-mail: dmzacardi@hotmail.com
}

Recebido em 06/04/2021 - Publicado em 19/04/2021

RESUMO Este estudo teve como objetivo caracterizar as embarcações pesqueira no município de Santarém. Os dados foram coletados por meio de entrevistas, realizadas no período de janeiro de 2017 a dezembro de 2018, em locais de movimentação da frota pesqueira e em diversos pontos da orla da cidade. Foram aplicados 150 formulários semiestruturados principalmente aos proprietários ou encarregados das embarcações de pesca e pescadores, além do acompanhamento de desembarques e observações diretas. As embarcações pesqueiras apresentavam dimensões que variam de 3 a 20 metros de comprimento, todas as unidades da frota de pesca possuíam a construção e estrutura em madeira evidenciando um sistema de produção artesanal. A frota pesqueira foi classificada em sete categorias: cascos, canoas, canoas motorizadas (rabetas), sapiaras, rabetão, bajaras e barcos geleiros, que se diferenciam pelo porte, modelo e tipo de propulsão. As embarcações mais frequentes nos portos de Santarém foram o grupo das canoas, em ordem decrescente de contribuição, estão as rabetas, canoas, cascos, rabetão e sapiaras, seguida pelos barcos geleiros e bajaras. As condições físicas do ambiente de várzea, com inúmeros canais, paranás e lagos que sofrem oscilações do nível de água são fatores determinantes para o tamanho das embarcações justificando a grande utilização dos cascos e canoas operando de fato na atividade pesqueira regional, associado, ainda a uma variação de técnicas de pesca que demandam um meio de transporte diferenciado. Portanto, este estudo comprova que o setor pesqueiro assume um papel importante na economia regional, além de abastecer a cidade de Santarém.

Palavras-chave: frota pesqueira, pesca artesanal, caracterização, aspectos operacionais, Baixo Amazonas.

\begin{abstract}
This study aimed to characterize fishing boats in the municipality of Santarém. The data were collected through interviews carried out from January 2017 to December 2018, in places where the fishing fleet was busy and at various points the edge of the city. During this period, 150 semi-structured forms were applied mainly to the owners or agents of fishing boats and fishermen who landed fish, as well as the monitoring of landings and direct observations. The fishing boats in activity in the municipality and registered in the present study had dimensions varying from 3 to 20 meters in length, all units of the fishing fleet had the construction and structure in wood evidencing an artisanal production system. The fishing fleet was classified into seven categories: "cascos", canoes, motorized canoes, "sapiaras", "rabetão", "bajaras" and "geleiras", which differ in size, model and type of propulsion. The most frequent boats in the ports of Santarém were the group of canoes, in descending order of contribution, are the "rabetas", canoes, "cascos", "rabetão" and "sapiaras", followed by the glaciers and "bajaras" boats. The physical conditions of the floodplain environment, with numerous canals, "paranás" and lakes that suffer fluctuations of the water level are determinant factors for the size of the boats justifying the great use of the hooves and canoes actually operating in the regional fishing activity, associated with a variation of fishing techniques that demand a differentiated means of transport. Therefore, this study proves that the fishing sector plays an important role in the regional economy, besides supplying the Santarém city.
\end{abstract}

Key words: fishing fleet, artisanal fishing, characterization, operational aspects, Lower Amazon. 


\section{Introdução}

A mesorregião do Baixo Amazonas no oeste do estado do Pará é rica em rios, lagos, canais, paranás e igarapés, além da presença marcante de uma extensa área de várzea apresentando uma vocação natural para a atividade pesqueira, devido os ambientes altamente produtivos os quais contribuem para uma alta piscosidade. Nessa região, a pesca se caracteriza como uma das atividades mais importantes e tradicional visando o comércio e o consumo de pescado (Zacardi et al., 2017; Serrão et al., 2019), constituindo-se como fonte vital de alimentos, ocupação de mão de obra e de renda para a população, especialmente para as pequenas comunidades (Cerdeira et al., 2000; Almeida et al., 2001; 2003; 2009).

O pescador é o explorador, caracterizado como profissional itinerante ou não, que faz o elo entre a riqueza dos recursos presentes nos rios e lagos com a população, principalmente, dos centros urbanos, e utiliza seu conhecimento acerca da região e das estratégias de captura das espécies, escolhendo o local situado a menor distância e de maior abundância dos recursos para realizar a pescaria (Ruffino, 2005; Corrêa et al., 2012).

As comunidades ribeirinhas utilizam diversas modalidades de pesca, com diferentes apetrechos e áreas de atuação distintas, onde a pesca comercial e de subsistência representam a maior fonte de geração de empregos do setor, sendo executada por uma variedade de embarcações pesqueiras, responsáveis pela condução dos pescadores e seus apetrechos para as áreas de exploração (Vaz et al., 2017; Côrrea et al., 2018). Mas, infelizmente, a pesca artesanal de águas interiores é frequentemente pouco documentada, o que leva a estimativas imprecisas da captura total e a equívocos sobre a importância social e econômica do setor.

O tipo de embarcação e a escolha da espécie alvo definem os fatores de produção e instrumentos necessários para a realização das pescarias, como os tipos de apetrechos a serem utilizados, os locais de pesca a serem explotados, a previsão de produção e o tempo em dias e horas a serem despendidos (Batista et al., 2007). Porém, as embarcações não devem ser tratadas apenas como meio de transporte, pois possuem um papel fundamental na cadeia produtiva, principalmente com relação as consequências econômicas e ambientais da pesca (Begot \& Vianna, 2014), no entanto, poucos estudos sobre a frota pesqueira têm sido desenvolvidos na região.

Neste contexto, o propósito geral do estudo é gerar informação básica necessária para o estudo da dinâmica da pesca, efetuando a classificação e caracterização da frota utilizada pelo pescador que abastece os principais portos de desembarque de pescado no centro urbano de Santarém, na Amazônia Oriental, avaliando suas similaridades e principais diferenças estruturais. Tais informações podem promover a identidade da pesca tradicional local, identificar padrões de uso, subsidiar o êxito na gestão do uso sustentável dos recursos pesqueiros e direcionar medidas de manejo adequadas ao setor pesqueiro regional.

\section{Material e Métodos}

$\mathrm{O}$ estudo foi realizado na cidade de Santarém, com uma área de $24.154 \mathrm{~km}^{2}$, situada entre os paralelos $02^{\circ} \mathrm{S}$ e $04^{\circ} \mathrm{S}$ e os meridianos $056^{\circ} \mathrm{W}$ e $054^{\circ} \mathrm{W}$ (Figura 1), localizada na confluência dos rios Tapajós e Amazonas, é considerada o quarto maior mercado de peixe da Amazônia brasileira, depois de Manaus, Belém e Tabatinga (Almeida et al., 2010), sendo o principal mercado consumidor do Baixo Amazonas, no estado do Pará.

Os dados foram coletados por meio de entrevistas, realizadas no período de janeiro 2017 a de dezembro de 2018, em locais de grande movimentação da frota pesqueira e de desembarque de pescados, como portos, feiras, mercados e em diversos pontos ao longo da orla da cidade.

Neste período, foram aplicados 150 formulários semiestruturados principalmente aos proprietários ou encarregados das embarcações de pesca e pescadores que desembarcavam pescado naquele local. Os formulários foram aplicados individualmente mediante adesão voluntária e ao final de cada entrevista foi solicitado ao informante que indicasse um ou mais pescadores. Os pesquisadores explicaram aos entrevistados a finalidade do trabalho e comunicaram que os dados obtidos serviriam apenas para fins acadêmicos e científicos, garantindo o anonimato e sigilo dos informantes. No final, cada entrevistado assinou o Termo de Autorização Livre e Esclarecido, autorizando sua participação e dando ciência de que foram totalmente elucidados quanto à pesquisa. 


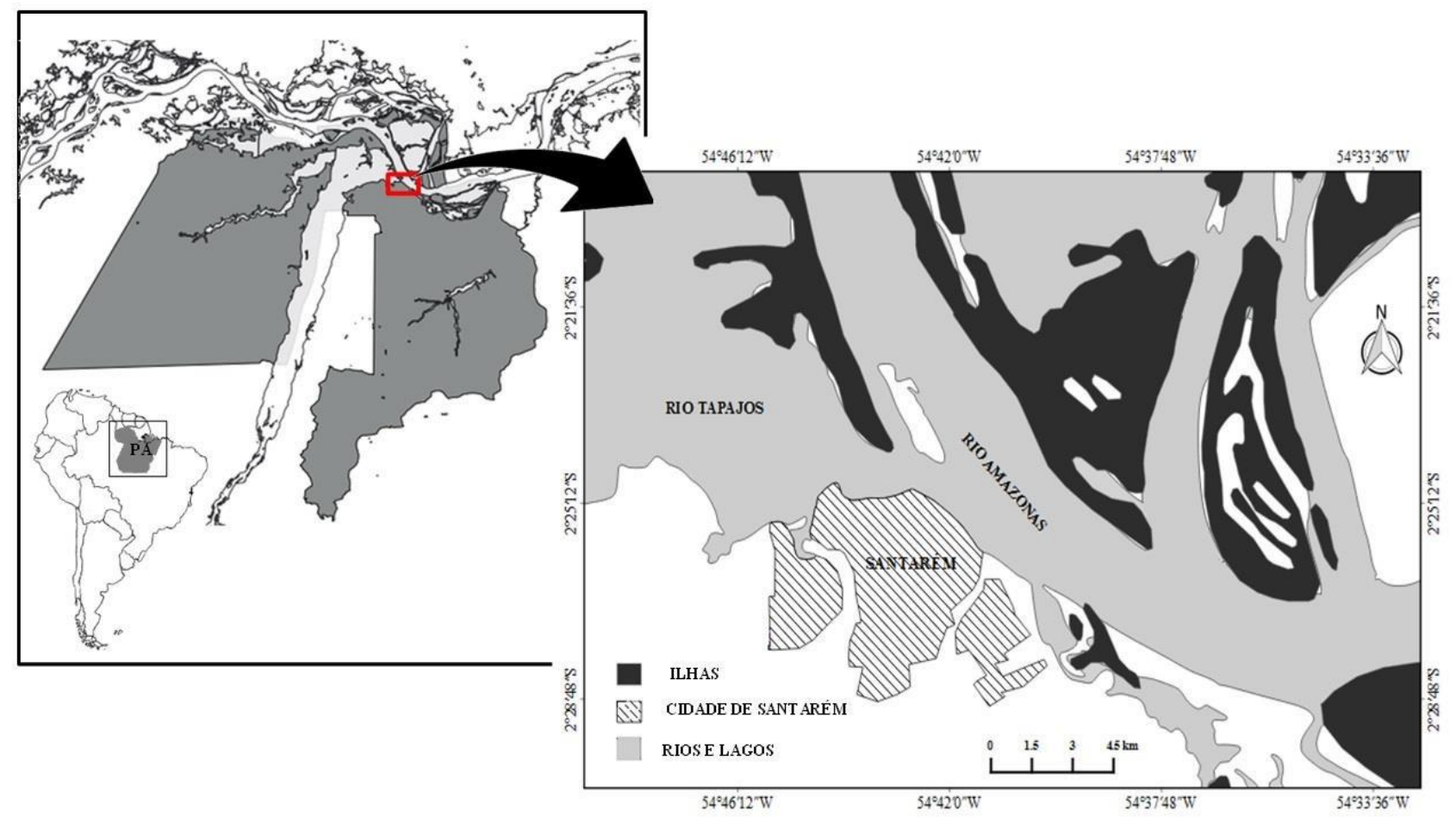

Figura 1. Localização da área de estudo, cidade de Santarém, Baixo Amazonas, estado do Pará.

Os formulários tinham como principal objetivo obter informações sobre a estrutura física das embarcações, tipo de embarcação, tamanho, potência do motor, capacidade de armazenamento, quantidade de canoas auxiliares, tempo de dedicação à atividade pesqueira, número de viagens por mês, principais apetrechos utilizados e locais de pesca, bem como destino da produção entre outras.

Durante as entrevistas foram realizadas observações "in loco" nas embarcações e registros fotográficos, com o objetivo de ilustrar as informações obtidas. As embarcações foram classificadas de acordo com suas características (capacidade de carga, material do casco, tipo de propulsão, comprimento, largura, número de tripulação, autonomia, conservação do pescado, entre outros.).

Os dados foram tabulados e armazenados em planilhas eletrônicas e analisados por meio de estatística descritiva, para obtenção das frequências de ocorrência e medida de tendência central (média) e medidas de dispersão dos dados (desvio padrão). Posteriormente os dados submetidos à análise estatística, resultaram na elaboração de gráficos, quadros, tabelas e distribuições de frequência.

\section{Resultados e Discussão}

A maioria dos entrevistados foi representado pelo sexo masculino, filiados a colônia de pescadores, com carteira profissional e possuindo mais de 10 anos de atividade (Tabela 1), fato que indica vasto conhecimento e experiência na área de atuação.

A afiliação em associações e colônias de pescadores, é uma garantia de uma série de benefícios como: seguro defeso e aposentadoria. O que poderia explicar o número elevado de proprietários ou encarregados das embarcações de pesca e pescadores artesanais registrados nas Colônias de Pescadores e Pescadoras (CPP).

Grande parcela dos pescadores nasceu e se criou no município de Santarém (68\%), embora alguns tenham origem de outras cidades do estado como: Abaetetuba, Alenquer, Altamira, Belém, Itaituba, Monte Alegre, Óbidos e Prainha que ao todo totalizaram (30\%), bem como, do Amazonas, oriundos de Manaus, Nhamundá e Parintins, na Amazônia Central (Tabela 2). 
Tabela 1. Informações gerais sobre os proprietários ou encarregados das embarcações de pesca e pescadores artesanais entrevistados, de janeiro 2017 a dezembro de 2018, na cidade de Santarém, estado do Pará.

\begin{tabular}{lc}
\hline \multicolumn{1}{c}{ Informantes N= 150 } & $(\boldsymbol{\%})$ \\
\hline Sexo & 7 \\
Feminino & 93 \\
Masculino & \\
Anos de atividade & 10 \\
$0-10$ & 34 \\
$11-20$ & 39 \\
$21-30$ & 12 \\
$31-40$ & 5 \\
$>40$ & \\
Carteira Profissional & 92 \\
Sim & 8 \\
Não & \\
Pertence a Colônia dos Pescadores e Pescadoras & 75 \\
Sim & 25 \\
Não & \\
\hline
\end{tabular}

Tabela 2. Participação absoluta e relativa (\%) dos locais de nascimento dos entrevistados, de janeiro 2017 a dezembro de 2018, na cidade de Santarém, estado do Pará.

\begin{tabular}{|c|c|c|c|}
\hline \multicolumn{2}{|c|}{ Local de nascimento dos pescadores } & \multirow{2}{*}{$\begin{array}{c}\text { Total } \\
1\end{array}$} & \multirow{2}{*}{$\frac{\text { Participação relativa (\%) }}{1}$} \\
\hline \multirow{9}{*}{ Pará } & Abaetetuba & & \\
\hline & Alenquer & 9 & 6 \\
\hline & Altamira & 1 & 1 \\
\hline & Belém & 2 & 1 \\
\hline & Itaituba & 8 & 5 \\
\hline & Monte Alegre & 10 & 7 \\
\hline & Óbidos & 6 & 4 \\
\hline & Prainha & 8 & 5 \\
\hline & Santarém & 102 & 68 \\
\hline \multirow{3}{*}{ Amazonas } & Manaus & 1 & 1 \\
\hline & Nhamundá & 1 & 1 \\
\hline & Parintins & 1 & 1 \\
\hline
\end{tabular}

Dentre os $75 \%$ dos pescadores cadastrados em CPP, $82 \%$ afirmaram pertencer a Z-20 em Santarém, no entanto, houve registro de pescadores da Z-11 de Monte Alegre, Z-12 de Manaus, Z-17 de Parintins, Z-19 de Óbidos, Z-28 de Alenquer, Z-31 de Prainha e Z-44 de Oriximiná (Tabela 3). 
Tabela 3. Participação absoluta e relativa (\%) das Colônias de Pescadores e Pescadoras, citados pelos entrevistados entre janeiro 2017 a dezembro de 2018, na cidade de Santarém, estado do Pará.

\begin{tabular}{ccc}
\hline Colônia de Pescadores e Pescadoras (CPP) & Total & Participação relativa \\
\hline CPP - Z11 Monte Alegre & 5 & $4 \%$ \\
CPP - Z12 Manaus & 1 & $1 \%$ \\
CPP - Z17 Parintins & 3 & $3 \%$ \\
CPP - Z19 Óbidos & 6 & $5 \%$ \\
CPP - Z20 Santarém & 92 & $82 \%$ \\
CPP - Z28 Alenquer & 1 & $1 \%$ \\
CPP - Z31 Prainha & 3 & $3 \%$ \\
CPP - Z44 Oriximiná & 1 & $1 \%$ \\
\hline Total & 112 & $100 \%$ \\
\hline
\end{tabular}

A variedade de origem dos pescadores atuantes e cadastrados em CPP de outros municípios, já era esperado, uma vez que Santarém está localizada em uma macrorregião de desembarque de pescado estratégica, conhecida como Baixo Amazonas, que vai de Parintins (AM) a Prainha (PA) e se configura em um importante entreposto pesqueiro majoritariamente de pescados capturados em pesqueiros locais e/ou de outros munícipios próximos. No entanto, é comum na região, o fato de muitos barcos de pesca (geleiras) desembarcarem em mais de um município e, às vezes, até mesmo em estados diferentes, indicando grande mobilidade da frota pesqueira entre diferentes portos e localidades (Batista et al., 2012).

Para a classificação da frota pesqueira do município de Santarém, as embarcações foram agrupadas por categorias, amplamente e culturalmente, utilizadas pelos pescadores ao nível regional, as quais resultaram em sete tipos de embarcações: cascos, canoas, canoas motorizadas (rabetas), sapiaras, rabetão, bajaras e barcos geleiros, que se diferenciam pelo porte, modelo e modo de propulsão. As embarcações apresentaram dimensões variando de 3 a 20 metros de comprimento. Em relação às características físicas, todas as unidades da frota de pesca possuíam a construção e estrutura em madeira evidenciando um sistema de produção essencialmente artesanal.

As embarcações constituídas de madeira, geralmente, são decorrentes do menor custo de aquisição, facilidade de manutenção que é efetuada pelo próprio pescador como a calafetagem, possibilidade de fabricação própria, utilizando maquinário simples e ferramentas manuais, além da facilidade em encontrar matéria-prima nas serrarias da região. Comumente, são utilizadas madeiras de itaúba Mezilaurus itauba (Meisn.) Taub. ou piquiá Caryocar villosum (Aubl.) Pers. para a construção das embarcações sejam elas de pequeno, médio ou grande porte.

\section{Cascos}

São embarcações rústicas de pequeno porte, sem casaria e sem urna (Tabela 4), propulsão realizada com auxílio de remo, normalmente, construídos a partir do entalhamento de um tronco de árvore, o que proporciona a característica de fundo arredondado e em formato de "U", confeccionados artesanalmente através de técnicas milenares repassadas entre gerações (Figura 2).

Os cascos possuem grande semelhança entre a proa e a popa, com amplitude de variação entre 3 e 5,5 metros de comprimento, capacidade de carga de 100 a $200 \mathrm{~kg}$, com tripulação de um a dois pescadores. Nesse tipo de embarcação, o pescador mantém o pescado no gelo (caixas móveis de poliestireno expandido isopor), no fundo do casco (peixe fresco - sem nenhuma forma de conservação), ou submerso na água por meio de sacos de ráfia presos a uma corda até o encerramento da atividade como forma de conservá-los vivos por um período mais longo. 
Tabela 4. Características das embarcações pesqueiras registradas entre janeiro 2017 a dezembro de 2018, na cidade de Santarém, estado do Pará.

\begin{tabular}{llccccc}
\hline Tipo & Casco & Convés & Casaria & $\begin{array}{c}\text { Comprimento } \\
\text { total }(\mathbf{m})\end{array}$ & Propulsão & $\begin{array}{c}\text { Capacidade } \\
\text { de carga (kg) }\end{array}$ \\
\hline Casco & Madeira & ausente & ausente & $3-5$ & remo & $100-200$ \\
Canoa & madeira & ausente & ausente & $3-7$ & remo ou vela & $170-450$ \\
Rabeta & madeira & ausente & ausente & $4-10$ & motor 4,5-6,5 HP & $200-500$ \\
Rabetão & madeira & ausente & ausente & $8-11$ & motor 7-15 HP & $400-1200$ \\
Sapiara & madeira & ausente & ausente & $4-7$ & motor 4,5-6,5 HP & $200-500$ \\
Bajara & madeira & $\begin{array}{c}\text { convés fechado ou } \\
\text { semifechado }\end{array}$ & $\begin{array}{c}\text { com ou sem } \\
\text { casaria }\end{array}$ & $6-14$ & motor de 13-22 HP & $800-4000$ \\
Geleira & madeira & $\begin{array}{c}\text { convés fechado } \\
\text { cou semi-fechado }\end{array}$ & casaria & $10-20$ & motor de 25-125 HP & $800-30000$ \\
\hline
\end{tabular}

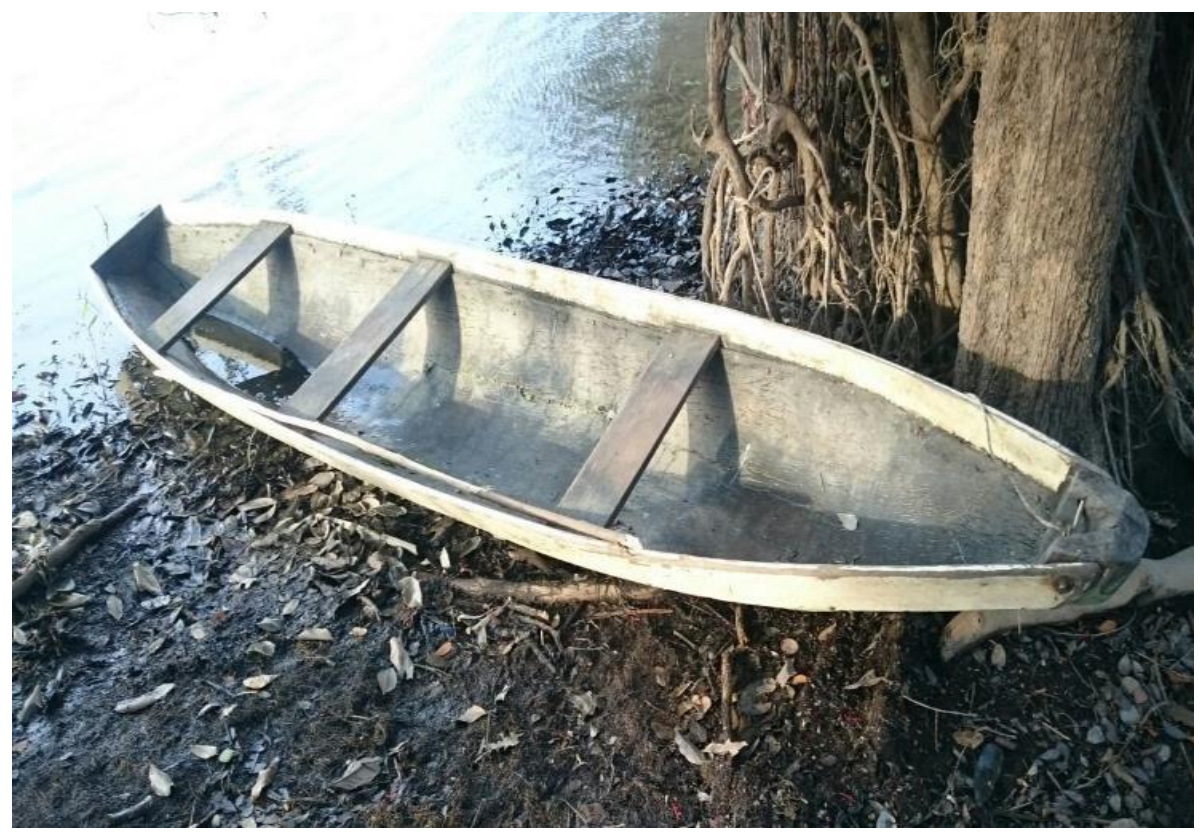

Figura 2. Casco utilizado em atividade de pesca na região de Santarém, Baixo Amazonas, estado do Pará.

São mais utilizados para pequenos deslocamentos e nas pescarias diárias próximas ao porto de desembarque e no entorno das residências dos pescadores. Os cascos atuam também como embarcações auxiliares de apoio à pesca artesanal em regiões mais afastadas e realizadas por barcos geleiras e rabetas.

\section{CANOAS}

São embarcações de pequeno a médio porte, construídas com tábuas devidamente bem plainadas e serradas, que definem o tamanho e a capacidade delas. Geralmente, são fabricadas em estaleiros (marcenarias), pois, sua confecção depende de maquinário próprio. As canoas variaram de 3 a $7 \mathrm{~m}$ de comprimento, com largura entre 1 a 1,8 m e propulsão à remo ou vela. $\mathrm{O}$ formato do fundo é arredondado em formato de "U", possui capacidade de carga total variável de 170 a $450 \mathrm{~kg}$, conforme o tamanho da embarcação. Não possui quilha, convés, casaria e porão para guardar gelo ou pescado (Figura 3). 


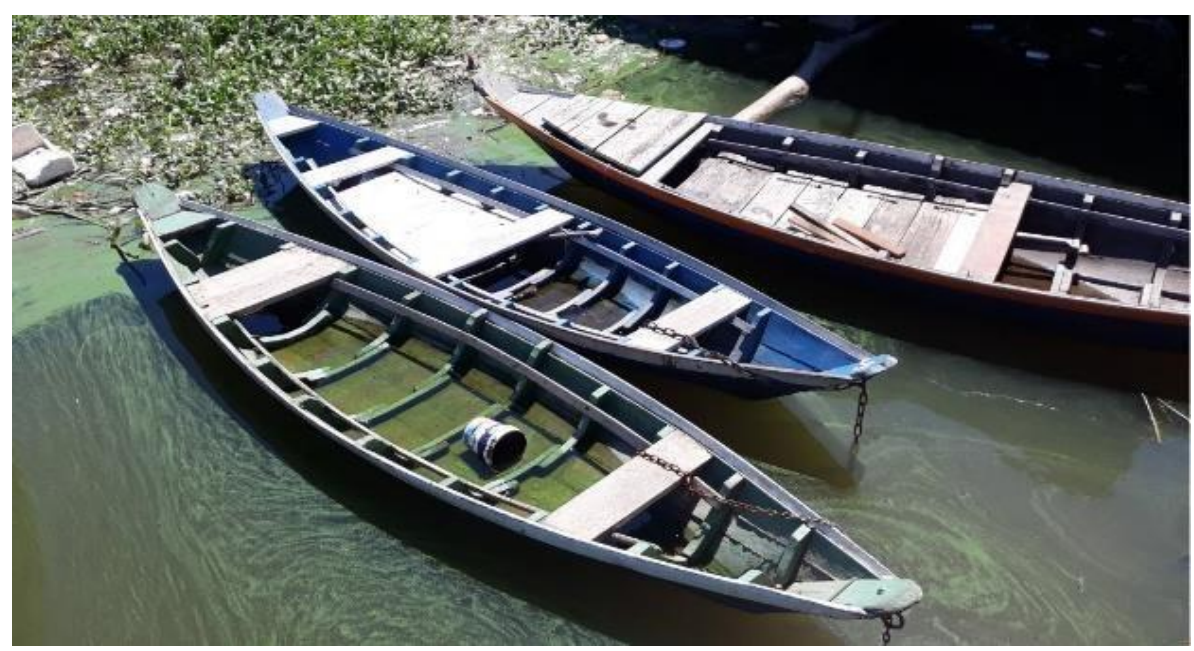

Figura 3. Canoas utilizadas em atividade de pesca na região de Santarém, Baixo Amazonas, estado do Pará.

A tripulação varia de 1 a 4 pescadores, atuam, tais como os cascos, dando suporte aos barcos geleiras. Conservam o pescado resfriado em caixas móveis de isopor ou em antigos freezers ou geladeiras que recebem abastecimento de gelo (Figura 4). Em alguns casos vendem o peixe "in natura" e possuem equipamentos de segurança como: colete, extintor e corda.

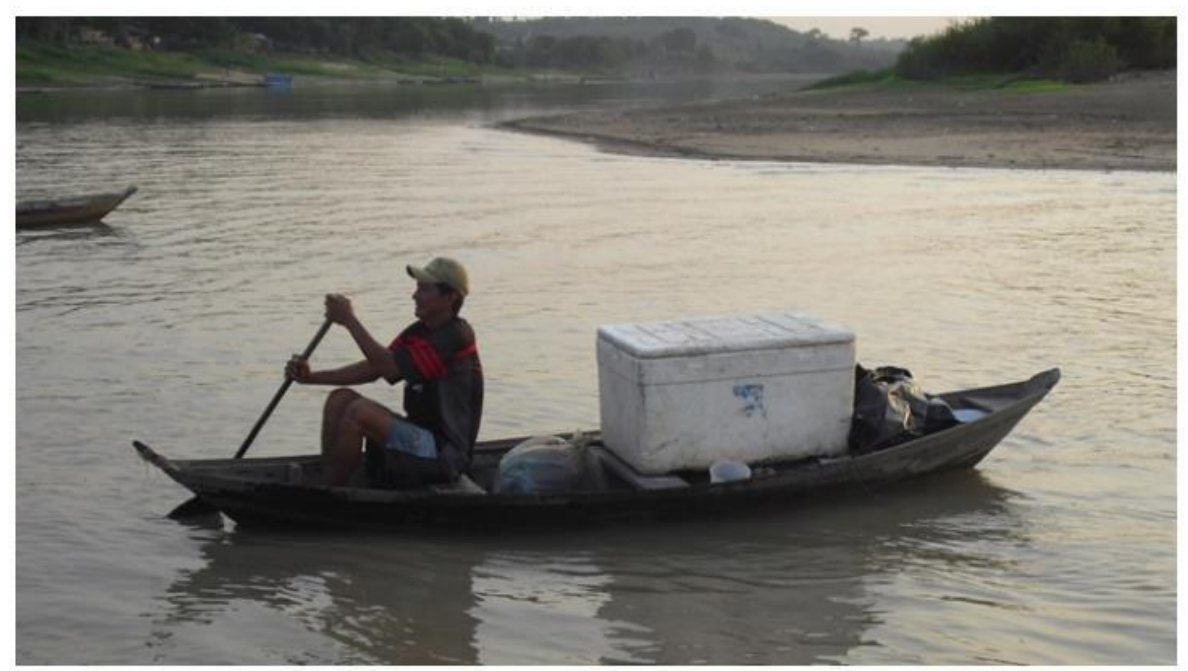

Figura 4. Pescador utilizando a canoa à remo e caixa de isopor com gelo para conservação do pescado, na região de Santarém, Baixo Amazonas, Pará.

As canoas possuem diversas estruturas denominadas de:

$\checkmark \quad \underline{\text { verdugues }}$ - ripa de madeira em alto relevo fixada na lateral externa da embarcação (Figura 5 A).

$\checkmark$ braços ou costelas - pedaços de madeira em formato de semi-arco que apoia internamente toda a estruturação do corpo da canoa (Figura 5 B).

$\checkmark$ cavernas - é o pedaço de madeira entre os braços, utilizado como reforço estrutural de madeira interno ao casco (Figura $5 \mathrm{C}$ ) 

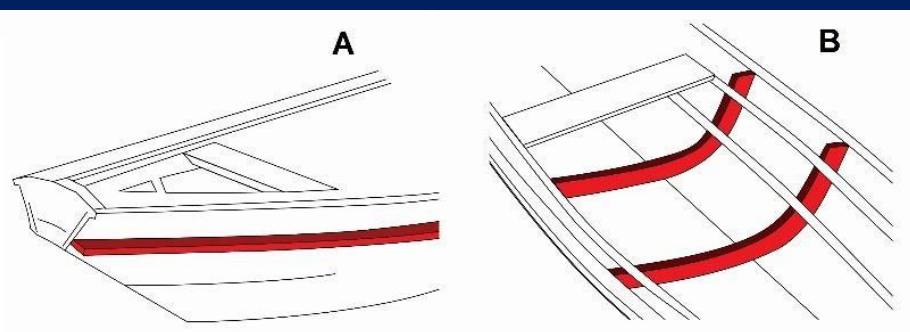

C

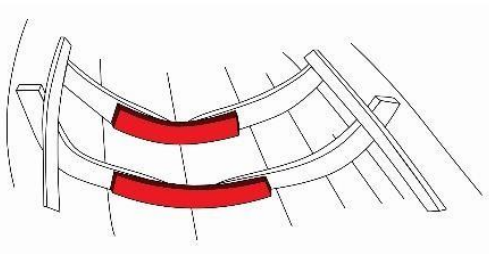

Figura 5. Estruturas das canoas de madeira utilizadas para a prática de pesca em Santarém, Baixa Amazonas, estado do Pará.

A - destaque do verdugue; B - destaque dos braços ou costelas; C - destaque das cavernas.

$\checkmark$ pavês ou bordadura - borda falsa de madeira do lado externo, no bordo superior da embarcação, aumentando sua capacidade de carga (Figura 6 A). Obs: encontrados também em cascos.

$\checkmark$ rodelas - peça de madeira, que sela a proa das canoas (Figura $6 \mathrm{~B}$ )

$\checkmark$ dormentes - é a ripa que fica por dentro da embarcação apoiando as tábuas que servem de bancos e os fogões (Figura $6 \mathrm{C}$ ).
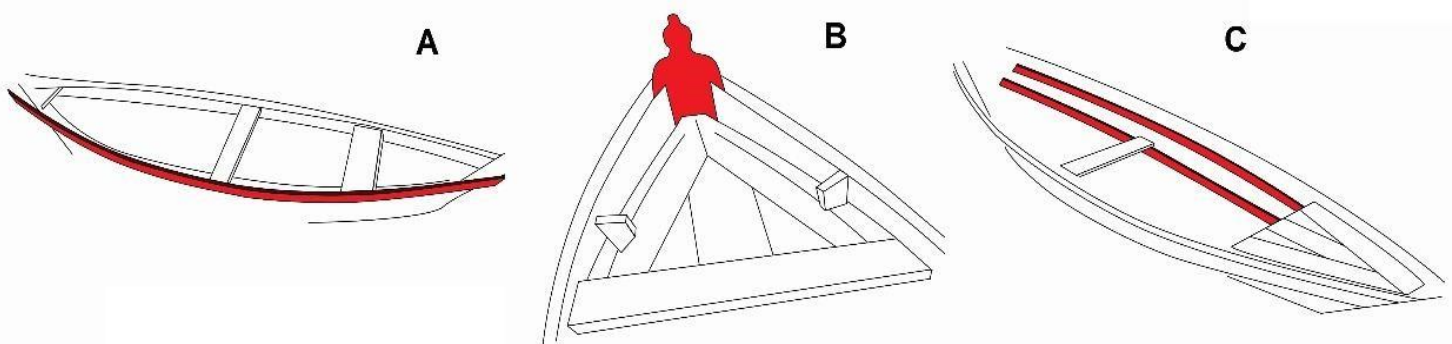

Figura 6. Estruturas das canoas de madeira utilizadas para a prática de pesca em Santarém, Baixo Amazonas, estado do Pará.

A - destaque do pavê ou bordadura; B - destaque da rodela; C - destaque dos dormentes.

$\checkmark$ fogões - assim chamada a face plana superior situada na extremidade da proa da canoa, onde o pescador e ajudantes de pesca costumam sentar (Figura $7 \mathrm{~A}$ ).

$\checkmark$ estivas - tábuas que formam o assoalho da embarcação (Figura 7 B).
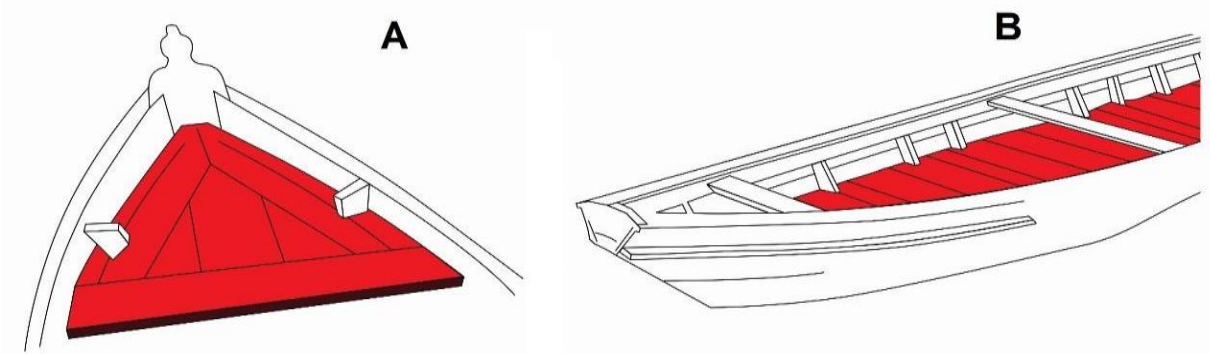

Figura 7. Estruturas das canoas de madeira utilizadas para a prática de pesca em Santarém, Baixo Amazonas, estado do Pará.

A - destaque do fogão; B - destaque das estivas.

As embarcações que operam na pesca de águas interiores na Amazônia são simples, unicamente artesanais e geralmente construídas em madeira (Batista et al., 2004). Vale ressaltar que as canoas apresentam maior eficiência econômica do que os barcos de grande porte, que, a despeito de seu tamanho e tecnologia, têm grandes custos operacionais (Almeida et al., 2012). 


\section{CANOAS MOTORIZADAS OU RABETAS}

A principal característica das canoas motorizadas é a forma de propulsão, são impulsionadas principalmente por motores do tipo rabeta de 4,5 a 6,5 HP de potência, cujo combustível é a gasolina (Figura 8).

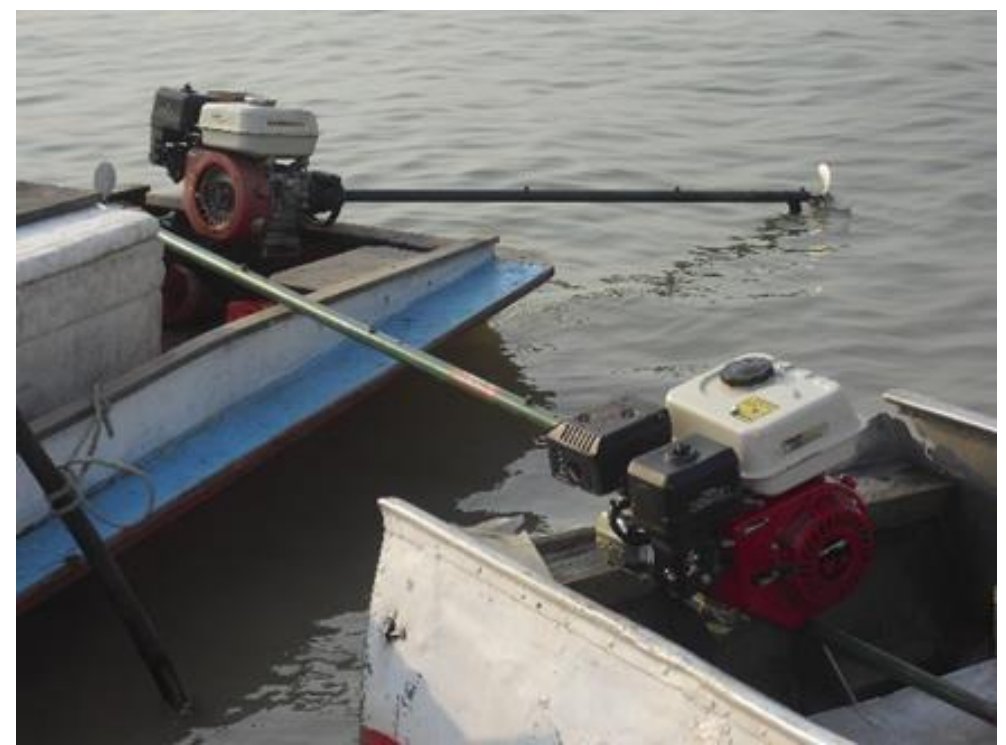

Figura 8. Motores do tipo rabeta utilizados nas canoas para a prática de pesca em Santarém, Baixo Amazonas, estado do Pará.

O motor tipo rabeta possui um sistema de transmissão em rabeta (varão com aproximadamente 1,5 a 2,0 $\mathrm{m}$, cardan direto, sem diferencial, aceleração automática, com hélice na ponta), que é instalado na parte posterior da canoa acoplado na "chapa" - uma peça de ferro onde se encaixa o pino do motor rabeta (Figura 9 A). As canoas motorizadas podem possuir o "flape" ou "flaps" - pedaço de madeira quadrado instalados no espelho de popa, usado para estabilizar e melhorar o desempenho da embarcação dentro d'água (Figura 9 B), e também, podem possuir uma "coberta" ou "tolda" - pequena cobertura, geralmente, confeccionada de madeira, recoberta com lona plástica ou zinco, muito utilizada em embarcações com pouca quantidade de cargas (Figura 9 C), sendo as suas outras características iguais à da canoa, sem quilha, sem convés, sem casaria e sem porão.

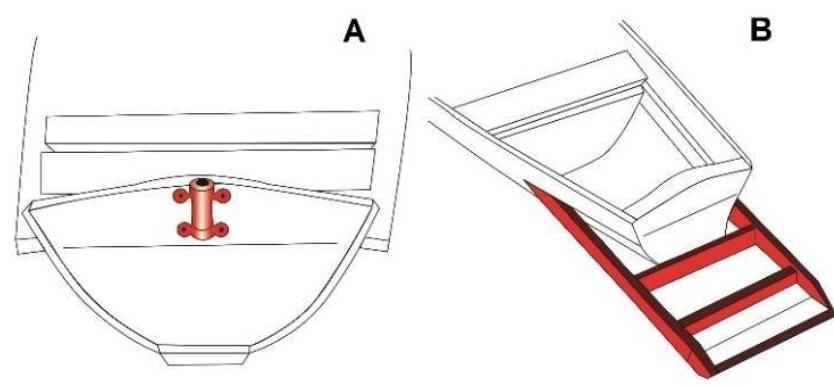

C

Figura 9. Estruturas das canoas motorizadas utilizadas para a prática de pesca em Santarém, Baixo Amazonas, estado do Pará. A - destaque da chapa; B - destaque do flape; C - destaque da tolda ou coberta.

As canoas motorizadas podem alcançar até $10 \mathrm{~m}$ de comprimento, $80 \mathrm{~cm}$ a $1,90 \mathrm{~m}$ de largura e transportar em média $500 \mathrm{~kg}$ de pescado, a tripulação varia de 1 a 4 pescadores, conservam o pescado resfriado no gelo em caixa de geladeira ou isopor e são utilizadas nas pescarias praticadas em áreas mais afastadas do porto de desembarque e atuam, tais como a canoa a remo e o casco, dando suporte aos barcos geleiras (Figura 10). 


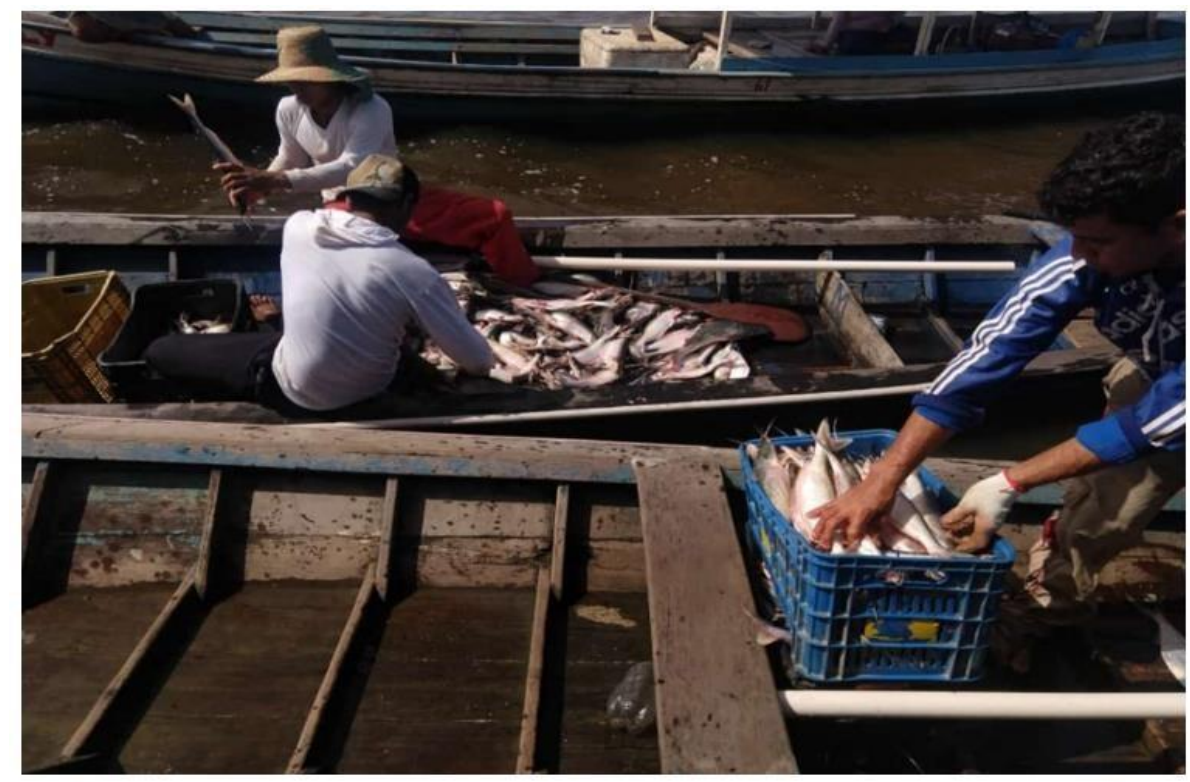

Figura 10. Canoas motorizadas utilizadas nas pescarias do mapará Hypophthalmus spp., abastecendo os barcos geleiras, na região de Alenquer, Baixo Amazonas, estado do Pará. Foto: Carlos Guimarães Farias Filho.

O uso de motores a gasolina ou a diesel e de caixas isotérmicas nas embarcações pesqueiras proporcionam maior capacidade de captura e armazenamento do pescado, permitindo pescarias de maior duração e em locais mais distantes da base, além de proporcionar a comercialização de peixe fresco nos mercados e feiras regionais (Batista \& Petrere, 2003; Batista et al., 2004).

\section{RABETÃO}

Canoas de madeira com tamanho variando de 8 a $11 \mathrm{~m}$ de comprimento, largura de 1,20 a 2,50 m, sendo impulsionadas principalmente por motores do tipo "rabetão" de 7,0 a 15 HP de potência (Figura 11), cujo combustível é a gasolina, não possuem casaria, convés e porão, mas podem conter tolda e quilha (Figura 12), sua capacidade total de carga varia de 400 a $1.200 \mathrm{~kg}$ e operam com 2 a 4 tripulantes. Conservam o pescado resfriado no gelo em caixa de geladeira ou isopor.

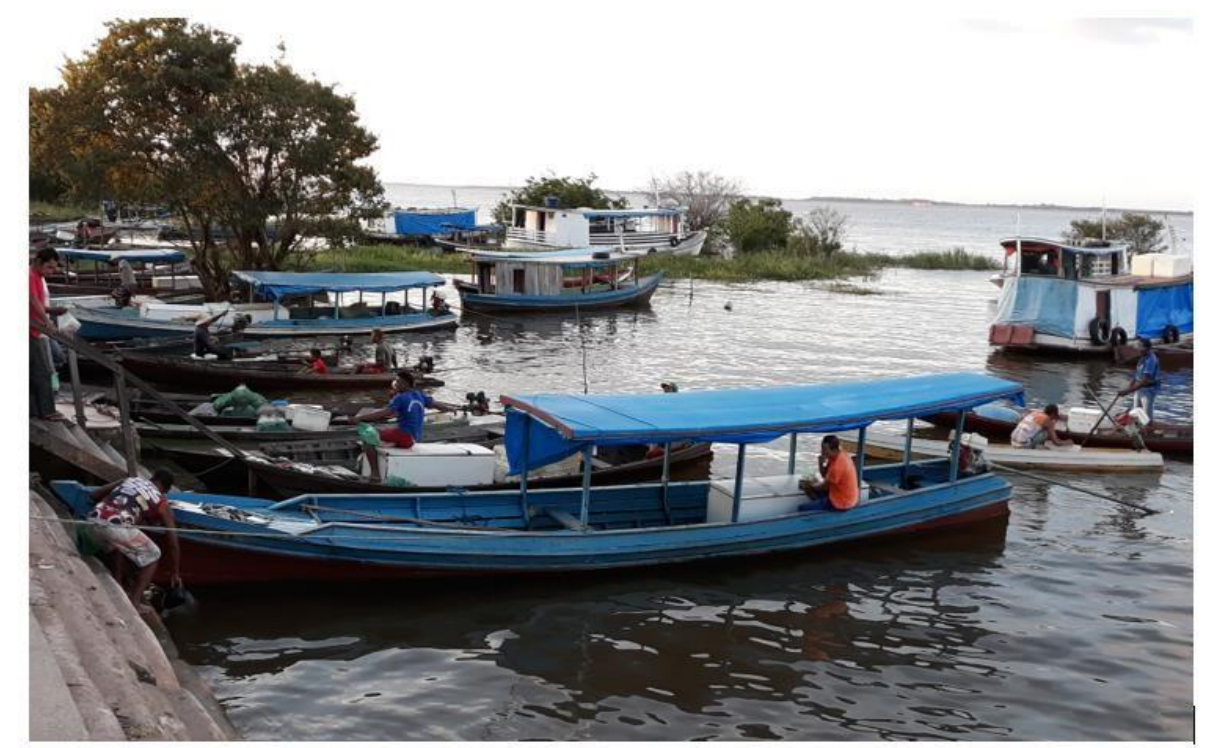

Figura 11. Rabetão desembarcando pescado no Porto dos Milagres em Santarém, Baixo Amazonas, estado do Pará. 


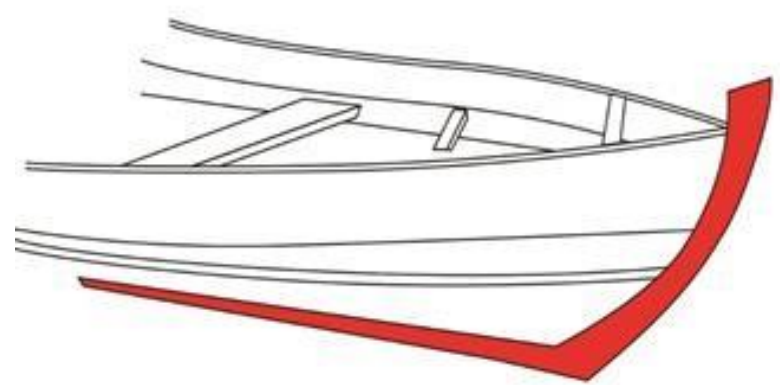

Figura 12. Quilha (estrutura em destaque) presente em embarcações utilizadas para a prática de pesca em Santarém, Baixo Amazonas, estado do Pará.

\section{SAPIARAS}

São as canoas de madeira com fundo chato (quadrado) e popa reta (Figura 13), apresentam o comprimento entre 4 e $7 \mathrm{~m}$ e largura de 1,2 a 2,0 m, não possuem casaria, convés e porão, com capacidade total de 200 a $500 \mathrm{~kg}$, movidas a propulsão de motor do tipo rabeta. Possuem capacidade de 2 a 3 tripulantes e conservam o pescado resfriado no gelo em caixa de geladeira ou isopor, tais como os cascos, as canoas a remo e as rabetas, também auxiliam nas pescarias dando suporte aos barcos geleiras.

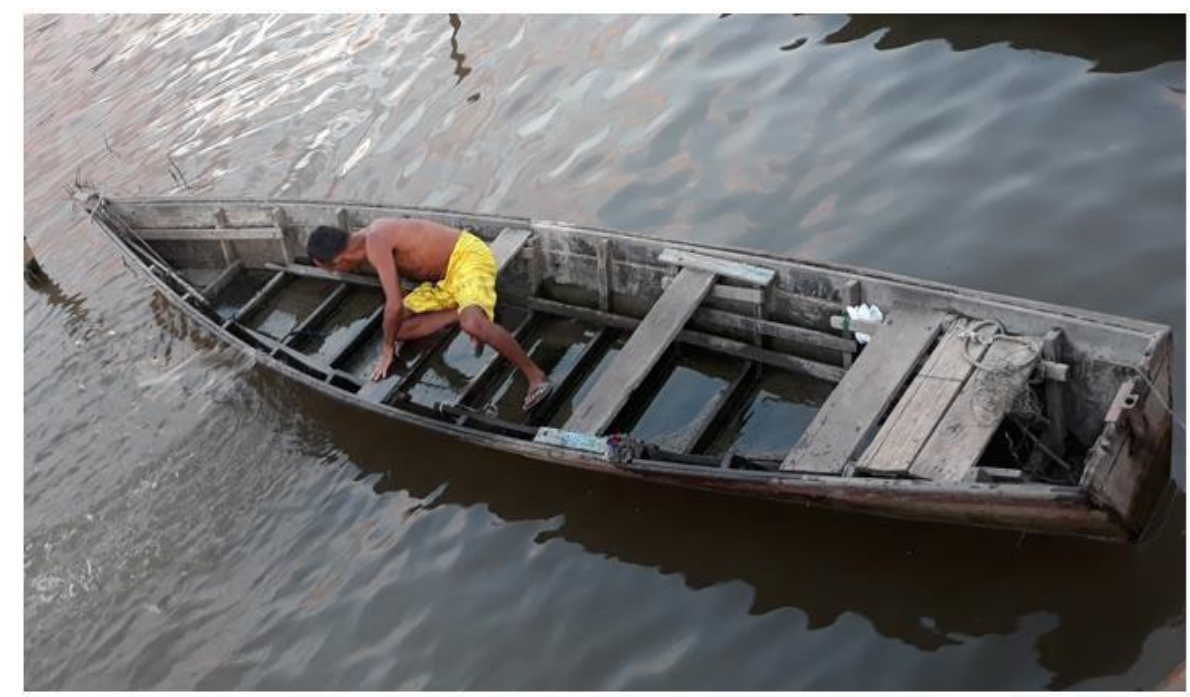

Figura 13. Canoa do tipo sapiara (fundo chato) utilizada em atividade de pesca em Santarém, Baixo Amazonas, estado do Pará.

\section{BAJARAS}

São embarcações que variam de pequeno a médio porte, construídas principalmente de madeira e propulsionadas por motores a diesel instalados no centro da embarcação, o fundo tem forma de quilha em "V" e tanto a proa quanto a popa são afuniladas (Figura 14), podem ou não apresentar casaria ou tolda/coberta, e quando não possuem, os pescadores protegem o motor de centro com lona plástica. Algumas bajaras podem ter dimensões parecidas com barcos de pequeno porte. 


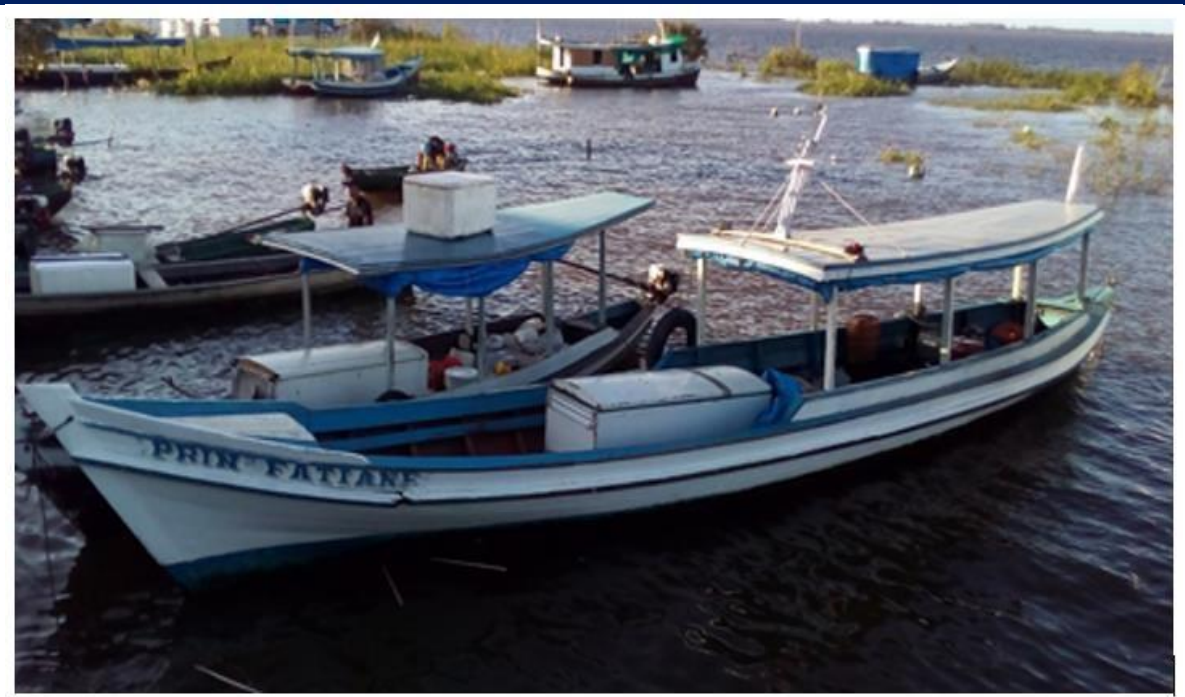

Figura 14. Bajara no cais do Porto dos Milagres, em Santarém, Baixo Amazonas, estado do Pará.

O motor de centro utilizado é estacionário e varia de 13 a 22 HP de potência à diesel (Figura 15), que por meio de um sistema de transmissão hidráulica desloca a embarcação, com "ponto morto" e "macha à ré". Tais manobras são proporcionadas pelo reversor, colocado entre o motor-propulsor e a hélice. É instalado na parte central da embarcação, tendo o leme na popa, alguns pescadores adaptam um volante próximo ao motor para facilitar as manobras.

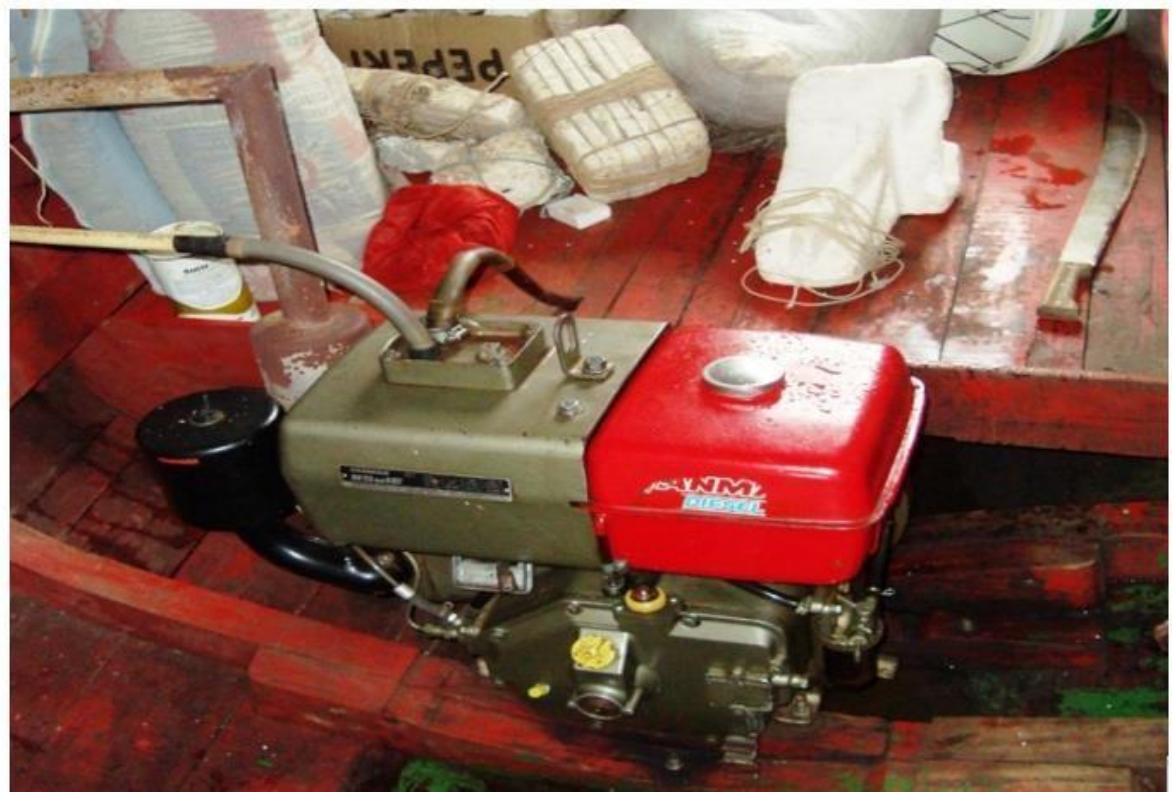

Figura 15. Motor de centro utilizados em bajaras e barcos geleiros, em Santarém, Baixo Amazonas, estado do Pará.

Este tipo de embarcação apresentou amplitude de variação de 6 a 14 metros de comprimento, a largura de 1,7 a 3,5 metros, com capacidade de 0,8 a 4 t. As bajaras são adaptadas a percorrerem distâncias mais longas e utilizadas para realizar viagens de pesca com duração média de 5 a 7 dias. A tripulação varia de dois a seis pescadores. O pescado é conservado e resfriado no gelo, principalmente em caixas de geladeira ou de isopor (Figura 16). Estas embarcações podem utilizar nas operações de pesca o apoio de cascos e/ou canoas a remo, sapiaras e canoas motorizadas para lançamento e recolhimento dos apetrechos de pesca, em quantidade variando de uma a três unidades. 


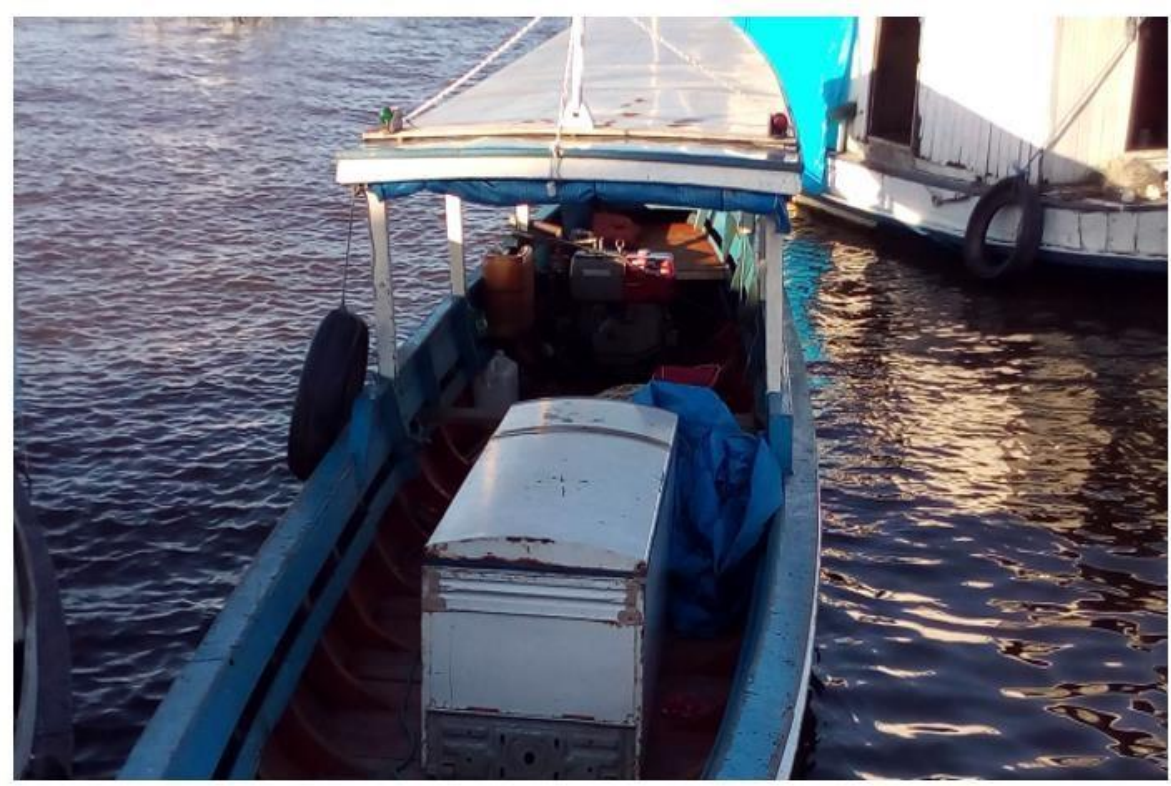

Figura 16. Bajara no cais do Porto dos Milagres, em Santarém, estado do Pará, transportando pescado resfriado e conservado dentro de carcaças de geladeiras abastecida com gelo, em Santarém, Baixo Amazonas, estado do Pará.

\section{BARCOS DE PESCA, BARCOS GELEIROS OU GELEIRAS}

São embarcações de madeira, principalmente itaúba (M. itauba), com fundo quilhado em forma de "V", propulsionadas por motor de centro movido a diesel, instalado no centro da embarcação, com potência de 25 a $125 \mathrm{HP}$, mas podem chegar até $200 \mathrm{HP}$. Os barcos variam de tamanho, com registro de amplitude de 10 a 19,80 m e largura de 1,80 a 3,60 m (Figura 17 A), os menores estocam o peixe em caixas de geladeira ou isopor (Figura 17 B), já os maiores são equipados com urnas no porão para estocagem de gelo e conservação do peixe (geleira) na proporção de 1:1 (Figura 17 C), com capacidade de armazenamento de até 30 toneladas, de forma que a qualidade do produto ainda é boa quando chega para o desembarque nos portos, feiras e mercados, além de fornecer pescado para os frigoríficos de Santarém.

As dimensões dos barcos e canoas se assemelham ao de algumas regiões já estudadas na Amazônia (Batista \& Petrere, 2003; Gonçalves \& Batista, 2008). De acordo com Batista et al. (2012) barcos menores são registrados no Alto Solimões com tamanho médio em torno de $10 \mathrm{~m}$, os maiores no Baixo Solimões com $13 \mathrm{~m}$ e no Baixo Amazonas com média de $11 \mathrm{~m}$ de comprimento, valor abaixo do encontrado no presente estudo.

É importante salientar que os barcos podem ou não ser responsáveis pela captura do pescado, geralmente, atuam como base para uma frota de embarcações menores (cascos, canoas a remo, rabetas entre outras) que operam de fato nas pescarias, lançando e recolhendo os apetrechos de pesca. Muitos barcos também compram peixes capturados por produtores de pequena escala e armazenam e transportam o pescado das áreas de pesca até os locais de desembarque e comercialização na sede do município (Figura 18).

Esse tipo de pesca é bem adaptado à grande natureza do rio Amazonas e de seus tributários, da mesma forma que serve de elo entre os pescadores e as feiras, mercados e entrepostos pesqueiros. A tonelagem de arqueação bruta pode chegar a $150 \mathrm{t}$, são adaptados também a percorrerem distâncias longas e utilizados para realizar viagens de pesca com duração média de 7 a 10 dias, com tripulação que pode variar de 4 a 6 pescadores (Tabela 5), além de utilizar canoas auxiliares, em quantidade variando de uma a dez unidades. Os barcos possuem aparelhos de navegação como GPS, rádio e sonar, além de equipamentos de segurança como colete, extintor e boias. 


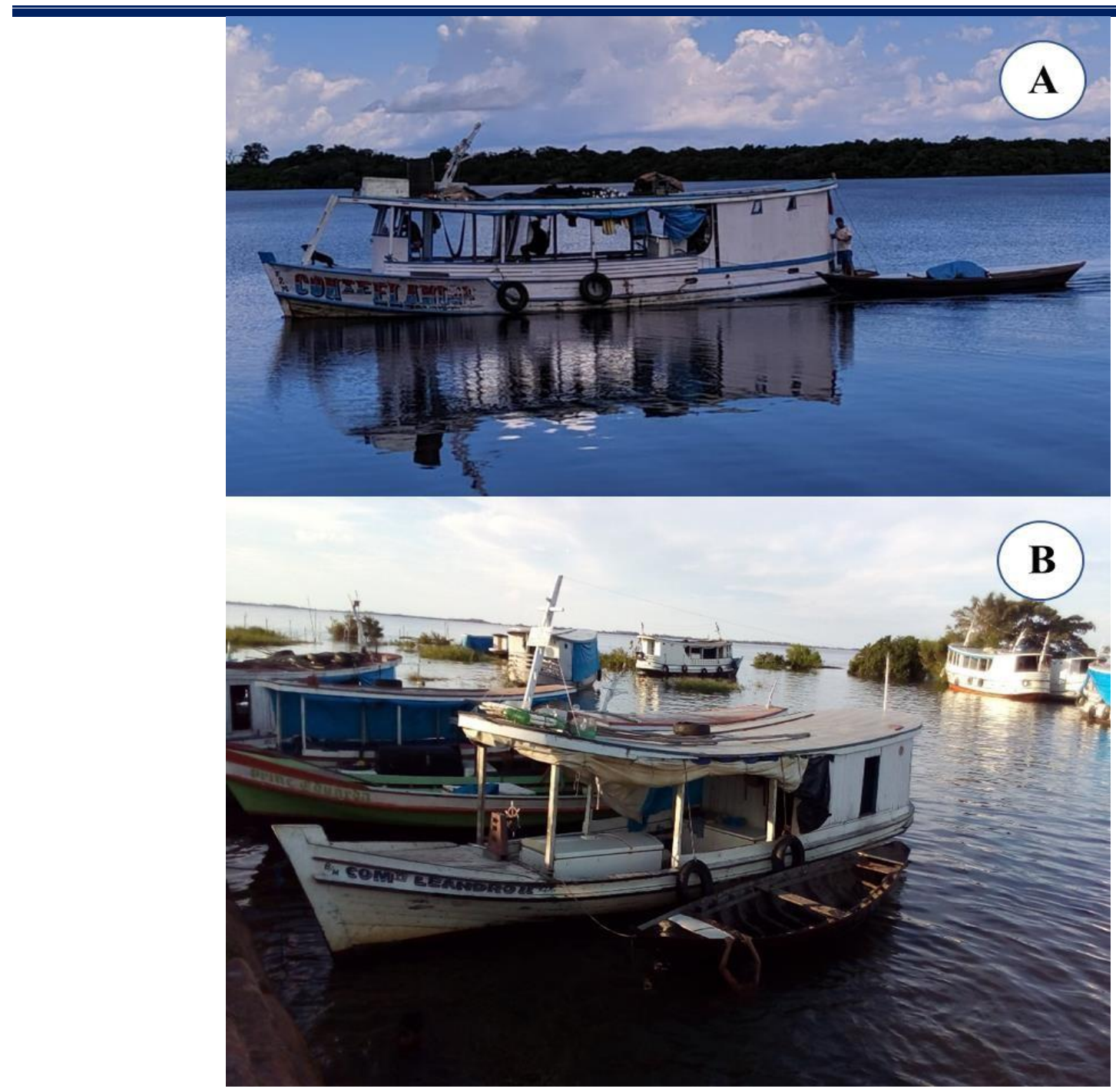

Figura 17. A - Barco geleiro, transportando embarcação auxiliar. Foto: Guillermo Moisés Bendezú Estupiñán. B Barco de pequeno porte transportando pescado resfriado e conservado dentro de carcaça de geladeira abastecida com gelo.

Esse tipo de pesca é bem adaptado à grande natureza do rio Amazonas e de seus tributários, da mesma forma que serve de elo entre os pescadores e as feiras, mercados e entrepostos pesqueiros. A tonelagem de arqueação bruta pode chegar a 150 t, são adaptados também a percorrerem distâncias longas e utilizados para realizar viagens de pesca com duração média de 7 a 10 dias, com tripulação que pode variar de 4 a 6 pescadores (Tabela 5), além de utilizar canoas auxiliares, em quantidade variando de uma a dez unidades. Os barcos possuem aparelhos de navegação como GPS, rádio e sonar, além de equipamentos de segurança como colete, extintor e boias.

Esses barcos podem, ainda, ser divididos de acordo com Isaac et al. (2004) pela sua modalidade de atuação: barcos pescadores que são embarcações que possuem a sua própria tripulação de pescadores, barcos compradores que percorrem as comunidades ribeirinhas ou locais de pesca, comprando pescado dos pescadores locais e comercializam em Santarém e barcos mistos que tanto levam pescadores como efetuam compras, em que a captura é realizada, na maioria das vezes, por pequenas canoas, que transportam o pescador até o local da pescaria, sendo o barco geleiro o depósito da produção, que é conservada em gelo. Diversos autores relatam que a produção dos pescadores artesanais, é voltada tanto para o consumo da família quanto para a comercialização, na região do Baixo Amazonas (Rabelo et al., 2017; Zacardi et al., 2017; Corrêa et al., 2018). 


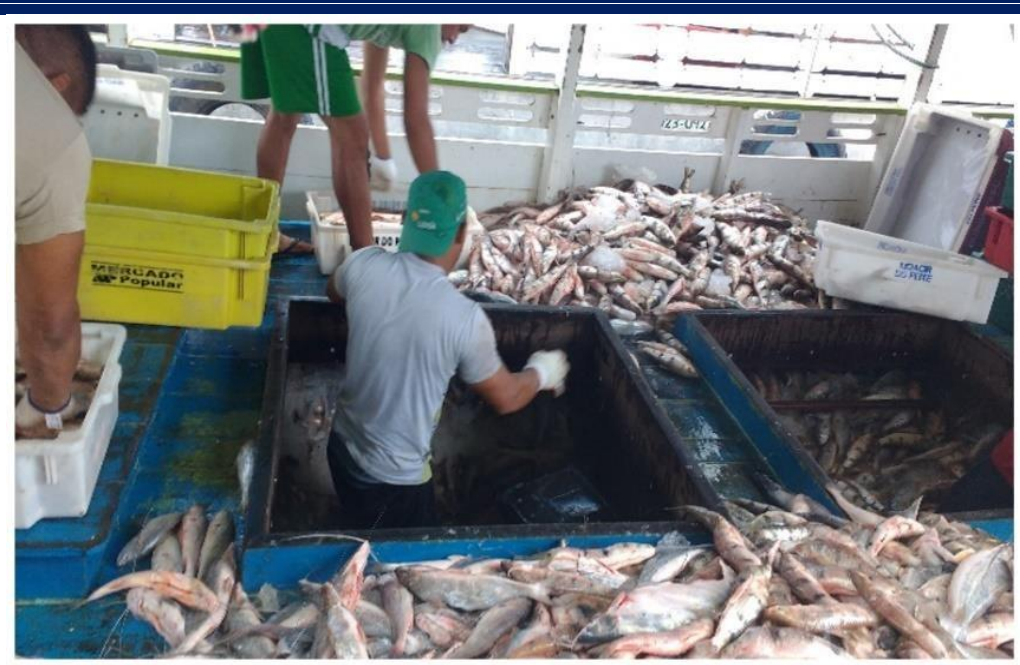

Figura 18. Barco geleiro desembarcando pescado em Santarém, Baixo Amazonas, estado do Pará.

Tabela 5. Características das pescarias por categoria de embarcação, em Santarém, Baixo Amazonas, estado do Pará.

\begin{tabular}{|c|c|c|c|c|}
\hline Categoria & $\begin{array}{l}\text { Número de } \\
\text { pescadores }\end{array}$ & Artes de pesca & $\begin{array}{c}\text { Conservação do } \\
\text { Pescado } \\
\end{array}$ & Comercialização \\
\hline Casco & $1-2$ & $\begin{array}{l}\text { caniço, flecha, linha de mão, } \\
\text { malhadeira, tarrafa, arpão }\end{array}$ & $\begin{array}{c}\text { in natura, gelo } \\
\text { em escama }\end{array}$ & diretamente ao consumidor \\
\hline Canoa & $1-4$ & $\begin{array}{c}\text { caniço, flecha, linha de mão, } \\
\text { malhadeira, espinhel, tarrafa, } \\
\text { arpão }\end{array}$ & $\begin{array}{l}\text { in natura, gelo } \\
\text { em escama }\end{array}$ & $\begin{array}{c}\text { diretamente ao consumidor ao } \\
\text { consumidor }\end{array}$ \\
\hline Rabeta & $1-4$ & $\begin{array}{l}\text { caniço, linha de mão, malhadeira, } \\
\text { espinhel, arrastão, tarrafa }\end{array}$ & gelo em escama & $\begin{array}{c}\text { diretamente ao consumidor ou } \\
\text { intermediário }\end{array}$ \\
\hline Rabetão & $2-4$ & $\begin{array}{l}\text { caniço, linha de mão, malhadeira, } \\
\text { espinhel, arrastão, tarrafa }\end{array}$ & gelo em escama & $\begin{array}{c}\text { diretamente ao consumidor ou } \\
\text { intermediário }\end{array}$ \\
\hline Sapiara & $2-3$ & $\begin{array}{l}\text { caniço, flecha, linha de mão, } \\
\text { malhadeira, espinhel, tarrafa }\end{array}$ & $\begin{array}{l}\text { in natura, gelo } \\
\text { em escama }\end{array}$ & diretamente ao consumidor \\
\hline Bajara & $2-6$ & $\begin{array}{l}\text { caniço, linha de mão, malhadeira, } \\
\text { espinhel, arrastão, tarrafa }\end{array}$ & gelo em escama & $\begin{array}{c}\text { diretamente ao consumidor ou } \\
\text { intermediário }\end{array}$ \\
\hline Geleira & $4-6$ & $\begin{array}{l}\text { caniço, linha de mão, malhadeira, } \\
\text { arrastão, tarrafa }\end{array}$ & gelo em escama & intermediário \\
\hline
\end{tabular}

Durante as amostragens do estudo, as embarcações mais frequentes nos portos de Santarém foram o grupo das canoas com 50\%, em ordem decrescente de contribuição, estão as rabetas (25\%), canoas (11\%), cascos $(7 \%)$, rabetão $(5 \%)$ e sapiaras $(3 \%)$, limitadas a pequenas distâncias e pouca capacidade de armazenamento de pescado, seguida pelos barcos geleiros (33\%) e bajaras (17\%) (Figura 19).

As canoas são mais numerosas, a princípio, mas não são quantificáveis por meios diretos nas condições atuais de registro, visto não serem sequer cadastradas pela Capitania dos Portos e, consequentemente, pela Secretaria de Desenvolvimento Agropecuário e da Pesca - SEDAP, que expede licenças de pesca às embarcações.

As condições físicas do ambiente de várzea, com inúmeros canais, paranás e lagos que sofrem oscilações do nível de água e grandes extensões de bancos de macrófitas flutuantes são fatores determinantes para o tamanho das embarcações justificando a grande utilização dos cascos e canoas operando de fato na atividade pesqueira regional, associado, ainda a uma variação de técnicas de pesca que demandam um meio de transporte diferenciado. 


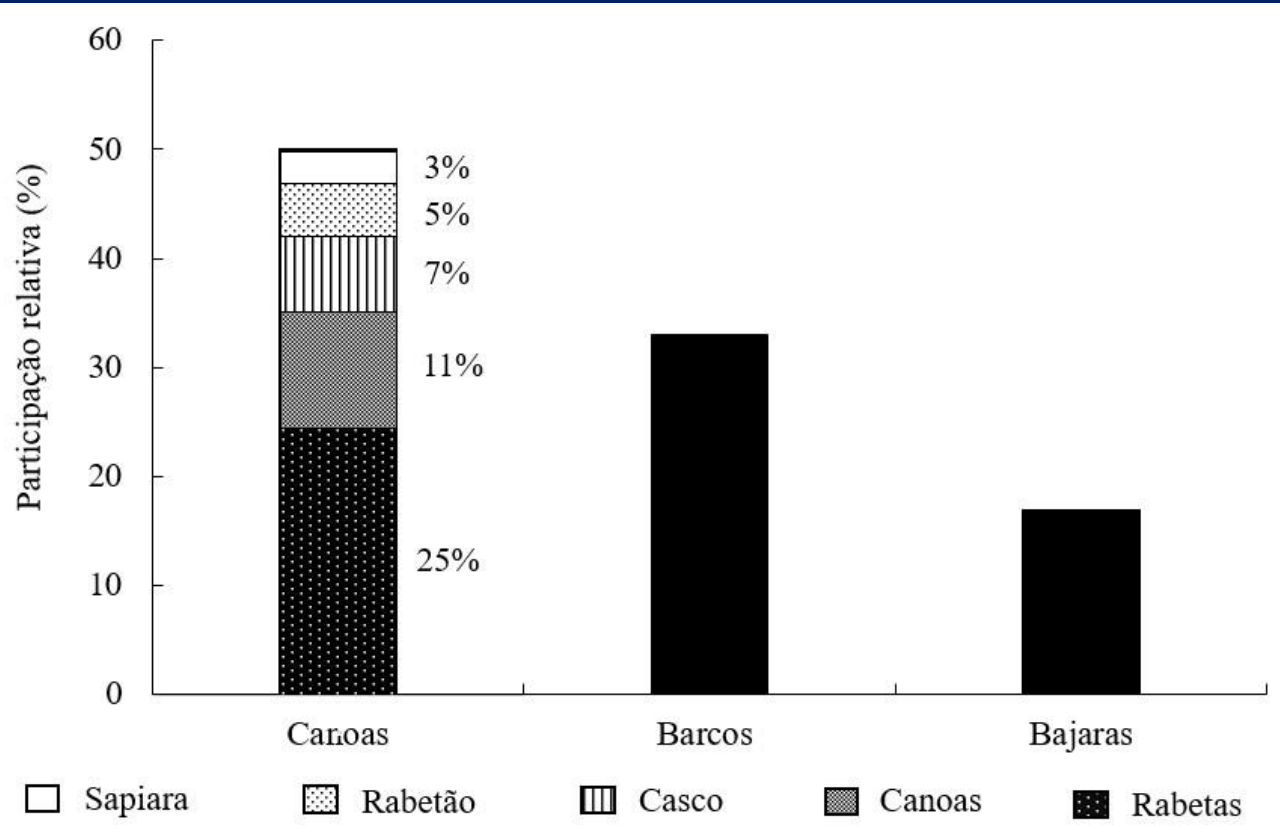

Figura 19. Participação relativa (\%) da ocorrência dos tipos de embarcações pesqueiras registradas entre janeiro 2017 a dezembro de 2018, nos portos de desembarque no município de Santarém, estado do Pará.

Almeida et al. (2001) caracterizando a frota pesqueira da região de Santarém, traçaram um perfil econômico da frota, evidenciando diferentes estratégias de pesca entre embarcações, mostrando, que os pequenos barcos pescadores são voltados para a pesca multiespecífica, que captura um grande número de espécies distintas e comercializa a produção no mercado regional, que oferece maior preço pelo produto, e, de outro lado, que os barcos geleiros de maior porte são especializados na pesca que tende a ser mais monoespecífica, voltada para o abastecimento dos frigoríficos, que oferecem preço mais baixo pelo pescado, mas absorvem maior volume.

O desenvolvimento pesqueiro também tem sido caracterizado por mudanças no perfil do pescador, especialmente pelo surgimento de uma classe de pescadores profissionais, o geleiro, que se dedica tempo integral à pesca. Baseado nos principais centros urbanos, o geleiro junto com sua equipe de pescadores, viaja em busca de peixe para vender nos principais mercados urbanos (Almeida, 2006; 2009). Hoje, o geleiro é a figura central no abastecimento, principalmente, nos grandes mercados e polos de desembarque da região.

Do ponto de vista tecnológico, a maioria da frota inclui embarcações com características de pesca artesanal de pequena escala, sem tecnologia de posicionamento, comunicação e localização de cardumes, nas quais as operações de pesca são realizadas manualmente.

Os proprietários ou encarregados das embarcações de pesca e pescadores artesanais entrevistados mostraram uma preferência pelas pescarias nos lagos da planície fluvial, citando os lagos (61\%), o rio (22\%) e os igarapés (10\%), nas proximidades da sede municipal, como principais pesqueiros explotados. Entretanto, existem pescadores que utilizam mais de um desses ambientes (7\%). Ao todo foram citados 21 locais de pesca e entre os ambientes com maior destaque estão o lago Maicá, o lago Grande e rio Amazonas.

Estes dados corroboram os estudos de Côrrea et al. (2012) e Vaz et al. (2017), que mostram a relevância dos lagos de várzea para a atividade pesqueira, tanto de subsistência quanto para a comercial multiespecífica. Todavia, diverge da tendência verificada nos trabalhos de Batista e Petrere (2003) e Cardoso e Freitas (2007) que observaram predominância de pescarias fluviais na região da Amazônia Central.

A maioria dos pescadores $(65 \%)$ citou o período da vazante e seca (verão), entre os meses de agosto e dezembro, como a melhor época para exercer a atividade pesqueira, devido as águas apresentarem seus níveis mais baixos proporcionando maior concentração dos peixes ao longo dos corpos d'água, diminuindo o tempo e esforço de pesca, situação já conhecida para a região (Vaz et al., 2017; Serrão et al., 2019; Zacardi \& Silva, 2019).

O ritmo de inundação é determinante para a existência, produtividade e interação da biota existente nas áreas de várzea, pois através desse processo acontecem as mudanças físico-químicas do ambiente. 
Consequentemente, as espécies respondem com uma série de adaptações morfológicas, anatômicas, fisiológicas, etológicas e as comunidades ícticas sofrem profundas modificações em sua estrutura (Barthem \& Fabré, 2004). Vários trabalhos afirmam que ciclo hidrológico determina a frequência e produção pesqueira na região amazônica (Batista \& Petrere, 2003; Freitas \& Rivas, 2006).

No município de Santarém de acordo com os entrevistados, existem diversos lugares de desembarque e comercialização do pescado, muito embora, os locais mais citados sejam o Porto dos Milagres e o Mercadão 2000, para as embarcações menores e a balsa Pontão do Peixe para as embarcações maiores (barcos geleiros).

A pesca é de suma importância nesta região, seja do ponto de vista econômico ou social e a maioria dos pescadores entrevistados se mostraram preocupados, pois nos últimos anos tem ocorrido uma redução no tamanho dos indivíduos e no volume de captura do pescado. De acordo com Cardoso e Haimovici (2011), a expansão da atividade em um contexto de decréscimo na abundância dos recursos pode levar, numa primeira fase, a imigração de pescadores de outros locais e, posteriormente, a um colapso com sérias consequências em termos de emprego e sustentabilidade social.

Frente a este cenário, ações de fortalecimento da cultura da pesca no município seriam importantes e contribuiriam para a coesão dos atores do setor pesqueiro regional no enfrentamento dos prováveis desafios e das mudanças de um futuro próximo.

\section{Conclusões}

A frota pesqueira de Santarém é composta na sua maioria por barcos de pequeno porte do grupo das canoas (cascos, canoas, canoas motorizadas ou rabetas, sapiaras, rabetão), sendo as principais responsáveis pelo apoio na captura e transporte do pescado que abastece a cidade, além de bajaras e barcos geleiros. Os cascos, canoas e canoas motorizadas são largamente utilizadas como embarcações auxiliares dos barcos geleiros nas pescarias. Canoas motorizadas tendem a ser utilizadas para explorar maior número de ambientes/pesqueiros, quando comparados aos barcos de pesca. A maioria das embarcações são equipadas de caixas isotérmicas com gelo para manter o pescado conservado até o local de desembarque e comercialização.

As embarcações utilizadas nas pescarias locais apresentaram dimensões que variam de 3 a 20 metros de comprimento, todas as unidades possuíam a construção e estrutura em madeira, geralmente de itaúba Mezilaurus itauba (Meisn.) Taub. ou piquiá Caryocar villosum (Aubl.) Pers. evidenciando um sistema de produção artesanal. A frota pesqueira, portanto, foi classificada em sete categorias: cascos, canoas, canoas motorizadas (rabetas), sapiaras, rabetão, bajaras e barcos geleiros, que se diferenciam pelo porte, modelo e tipo de propulsão. As embarcações apresentaram propulsão manual (à remo) e com o auxílio de motores rabeta $(4,5$ a $15 \mathrm{HP})$ e de centro (13 a $125 \mathrm{HP})$. Logo, a frota pesqueira atuante em Santarém pode ser caracterizada como artesanal e de pequena escala.

\section{Referências}

Almeida, O.T., Amaral, L., Riveiro, S. \& Silva, C.N. (2012). Caracterização do pescador e da frota pesqueira comercial de Manoel Urbano e Sena Madureira (AC) e Boca do Acre (AM). Novos cadernos do NAEA, 15(1): 291-309.

Almeida, O.T., Lorenzen K. \& Mcgrath, D. (2003). Commercial fishing in the Brazilian Amazon: regional differentiation in fleet characteristics and efficiency. Fisheries Management and Ecology, 10(1): 109-115.

Almeida, O T., Lorenzen, K. \& Mcgrath, D. (2006). A frota comercial pesqueira na Amazônia e o co-manejo no Baixo Amazonas. In: Almeida, O. (Ed.). Manejo de pesca na Amazônia. Manaus: ProVárzea, 2006. p. 3750 .

Almeida, O.T., Lorenzen, K. \& Mcgrath, D. (2009). Fishing agreements in the lower Amazon: for gain and restraint. Fisheries Management and Ecology, 16(1): 6167.

Almeida, O.T., Mcgrath, D. \& Ruffino, M.L. (2001). The commercial fisheries of the lower Amazon: an economic analysis. Fisheries Management and Ecology, 8(1): 253-269. 
Almeida, O.T., Mcgrath, D., Ruffino, M. \& Rivero, S. (2010). Estrutura, dinâmica e economia da pesca comercial do baixo Amazonas. Novos cadernos do NAEA, 12(2): 175-180.

Barthem, R.B. \& Fabré, N.N. (2004). Biologia e diversidade dos recursos pesqueiros da Amazônia. In: Ruffino, L. M. (Ed.). (pp. 17-62). A pesca e os recursos pesqueiros na Amazônia brasileira. Manaus: ProVárzea.

Batista, V.D.S., Chaves, M.P.S.R., Faria-Junior, C.H., Oliveira, M.F.G., Inhamus, A.J. \& Bandeira, C.F. (2007). Caracterização socioeconômica da atividade pesqueira e da estrutura de comercialização do pescado na calha Solimões-Amazonas. In: Ruffino, M.L. (Ed). (pp. 19-58). O setor pesqueiro na Amazônia: análise da situação atual e tendências do desenvolvimento a indústria da pesca. Brasília: Editora do Ibama.

Batista, V.D.S. \& Petrere, M.J. (2003). Characterization of the commercial fish production landed at Manaus, Amazonas State, Brazil. Acta Amazonica, 33(1): 53-66.

Batista, V.S., Isaac, V.J., Fabré, N.N., Gonzalez, J.C.A., Almeida, O.T., Rivero, S., Júnior, J.N.O., Ruffino, M.L., Silva, C.O. \& Saint-Paul, U. (2012). Peixes e pesca no Solimões-Amazonas: uma avaliação integrada. Brasília: Ibama/ProVárzea.

Batista, V.S., Isaac, V.J. \& Viana, J.P. (2004). Exploração e manejo dos recursos pesqueiros da Amazônia. In: Ruffino, M.L. (Ed.). (pp. 63-151). A pesca e os recursos pesqueiros na Amazônia brasileira. Manaus: ProVárzea/Ibama.

Begot, L.H. \& Vianna, M. (2014). A frota pesqueira costeira do estado do Rio de Janeiro. Boletim do Instituto de Pesca, 40(1): 79-94.

Cardoso, L. G.; Haimovici, M. (2011). Caracterização tecnológica, social, econômica e ecológica da atividade pesqueira sediada em Passo de Torres, Santa Catarina, Brasil. Boletim do Instituto de Pesca, 37(3): 275-288.

Cardoso, R.S. \& Freitas, C.E.C. (2007). Desembarque e esforço de pesca da frota pesqueira comercial de Manicoré (médio Rio Madeira), Amazonas, Brasil. Acta Amazonica, 37(4): 605-612.

Cerdeira, R.G.P., Isaac, V.J.; Ruffino, M.L. (2000). Captura de pescado nas comunidades do Lago Grande de Monte Alegre-PA, Brasil. Manaus: ProVárzea/Ibama.

Corrêa, J.M.S., Rocha, M.S., Santos, A.A., Serrão, E.M. \& Zacardi, D.M. (2018). Caracterização da pesca artesanal no Lago Juá, Santarém, Pará. Revista Agrogeoambiental, 10(2): 61-74.

Corrêa, M.A.A., Kahn, J.R. \& Freitas, C.E.C. (2012). A pesca no município de Coari, Estado do Amazonas, Brasil. Revista Brasileira de Engenharia de Pesca, 6(2): 1-12.

Freitas, C E.C. \& Rivas, A.A.F. (2006). A pesca e os recursos pesqueiros na Amazônia Ocidental. Ciência e Cultura, 58(1): 30-31.

Gonçalves, C. \& Batista, V.S. (2008). Avaliação do desembarque pesqueiro efetuado em Manacapuru, Amazonas, Brasil. Acta Amazonica, 38(1): 135-144.

Isaac, V.J., Silva. C.O. \& Ruffino M.L. (2004). A pesca no Baixo Amazonas. In: Ruffino. M. L. (Ed.). (pp. 185-212). A pesca e os recursos pesqueiros na Amazônia brasileira. Manaus: ProVárzea/Ibama.

Rabelo, Y.G.S., Vaz, E.M. \& Zacardi, D.M. (2017). Perfil socioeconômico dos pescadores artesanais de dois lagos periurbanos de Santarém, estado do Pará. Revista Desafios, 4(3): 73-82.

Ruffino, M.L. (2005). Gestão do uso dos recursos pesqueiros na Amazônia. ProVárzea/Ibama.

Serrão, E.M., Rabelo, Y.G.S. \& Côrrea, J.M.S. (2019). Caracterização da atividade pesqueira em dois lagos de inundação amazônico, Santarém, Pará. In: Ribeiro; J.C. \& Santos, C.A. (pp. 1-12). A face multidisciplinar das ciências agrárias 2. Ponta Grossa: Atena Editora.

Vaz, E.M., Rabelo, Y.G.S., Corrêa, J.M.S. \& Zacardi, D.M. (2017). A pesca artesanal no lago Maicá: aspectos socioeconômicos e estrutura operacional. Biota Amazônia, 7(4): 6-12. 
Zacardi, D. M., Ponte, S.C.S. \& Silva, A.J.S. (2014). Caracterização da pesca e perfil dos pescadores artesanais de uma Comunidade às margens do rio Tapajós, estado do Pará. Amazônia: Ciência \& Desenvolvimento, 10(19): 129-148.

Zacardi, D.M., Saraiva, M.L. \& Vaz, E.M. (2017). Caracterização da pesca artesanal praticada nos lagos Mapiri e Papucu às margens do rio Tapajós, Santarém, Pará. Revista Brasileira Engenharia Pesca, 10(1): 3244.

Zacardi, D.M. \& Silva, F.M. (2019). A pesca no rio Arapiuns: estudo de caso com os pescadores da comunidade Vila Brasil, Santarém, Pará. In: Ribeiro; J.C. \& Santos, C.A. (pp. 1-16). A face multidisciplinar das ciências agrárias 3. Ponta Grossa: Atena Editora. 